ARTICLE

\title{
Tuning selectivity of electrochemical reactions by atomically dispersed platinum catalyst
}

Chang Hyuck Choi ${ }^{1,2}$, Minho Kim³ ${ }^{3}$, Han Chang Kwon', Sung June Cho ${ }^{4}$, Seongho Yun ${ }^{1}$, Hee-Tak Kim', Karl J.J. Mayrhofer ${ }^{2,5}$, Hyungjun $\mathrm{Kim}^{3}$ \& Minkee Choi ${ }^{1}$

Maximum atom efficiency as well as distinct chemoselectivity is expected for electrocatalysis on atomically dispersed (or single site) metal centres, but its realization remains challenging so far, because carbon, as the most widely used electrocatalyst support, cannot effectively stabilize them. Here we report that a sulfur-doped zeolite-templated carbon, simultaneously exhibiting large sulfur content (17 wt\% S), as well as a unique carbon structure (that is, highly curved three-dimensional networks of graphene nanoribbons), can stabilize a relatively high loading of platinum ( $5 \mathrm{wt} \%$ ) in the form of highly dispersed species including site isolated atoms. In the oxygen reduction reaction, this catalyst does not follow a conventional fourelectron pathway producing $\mathrm{H}_{2} \mathrm{O}$, but selectively produces $\mathrm{H}_{2} \mathrm{O}_{2}$ even over extended times without significant degradation of the activity. Thus, this approach constitutes a potentially promising route for producing important fine chemical $\mathrm{H}_{2} \mathrm{O}_{2}$, and also offers opportunities for tuning the selectivity of other electrochemical reactions on various metal catalysts.

\footnotetext{
${ }^{1}$ Department of Chemical and Biomolecular Engineering, Korea Advanced Institute of Science and Technology, Daejeon 305-701, Korea. ${ }^{2}$ Department of Interface Chemistry and Surface Engineering, Max-Planck-Institut für Eisenforschung GmbH, Max-Planck-Strasse 1, 40237 Düsseldorf, Germany. ${ }^{3}$ Graduate School of EEWS, Korea Advanced Institute of Science and Technology, Daejeon 305-701, Korea. ${ }^{4}$ Department of Applied Chemical Engineering, Chonnam National University, Yongbong 300, Buk-gu, Gwangju 500-757, Korea. ${ }^{5}$ Forschungszentrum Jülich, 'Helmholtz-Institut Erlangen-Nürnberg' (IEK 11),

Nägelsbachstrasse 49b, 91052 Erlangen, Germany. Correspondence and requests for materials should be addressed to H.K. (email: linus16@kaist.ac.kr) or to M.C. (email: mkchoi@kaist.ac.kr).
} 
$\mathrm{N}$ oble metals are the most widely used catalysts in industry because of their high activity, selectivity and stability in many important reactions. The catalysts often consist of finely dispersed metal nanoclusters on porous supports to maximize the active surface area. In principle, as the size of the metal cluster further decreases to a sub-nanometre scale and ultimately to an atomic level (atomically dispersed metal catalyst), the catalytic properties are drastically changed ${ }^{1,2}$. Increased interaction with a support can modulate the electronic properties of metal catalysts and reduced metal-metal coordination can suppress chemical reactions requiring multiatom sites. This can provide unique opportunities for tuning activity and chemoselectivity ${ }^{3}$. Because the atomically dispersed metal catalysts (they are also called 'single-atom catalysts' in the literature) are highly unstable and prone to agglomeration due to their high surface energy, metal oxide supports (or alloys ${ }^{4-7}$ ) providing strong metal-support interactions, for example, $\mathrm{CeO}_{2}$ (refs 8-13), $\mathrm{FeO}_{x}$ (refs 14-18), $\mathrm{TiO}_{2}$ (refs 19,20), $\mathrm{Al}_{2} \mathrm{O}_{3}$ (refs 21-25) and silica/zeolite with and without alkali ions ${ }^{26-33}$, are typically indispensable for their stabilization.

In principle, atomically dispersed metal catalysts can exhibit distinct properties not only in chemical reactions but also in electrochemical reactions. Unfortunately, metal oxide supports are generally insulators or semiconductors with low electron conductivities. Moreover, they are unstable under corrosive electrochemical operating conditions ${ }^{34}$. In contrast, carbonbased materials can provide outstanding stability, good electron conductivity and large surface area, and are therefore considered as ideal candidates for supports in electrocatalysis. The carbons, however, show inert characteristics and do not provide strong metal-support interactions ${ }^{35}$. Hence, surface modifications (for example, oxidation) are often required to stabilize metal clusters even of a few nanometres in diameter ${ }^{36}$. Recently, highly sophisticated techniques such as atomic layer deposition ${ }^{37,38}$, mass-selected soft landing ${ }^{39}$ and arc discharge ${ }^{40}$ have been used to prepare sub-nanometre noble metal clusters on carbon surfaces. Nevertheless, these techniques still generate physical mixtures of atomically dispersed species as well as nanoscale clusters, which render the interpretation of the electrocatalytic performance rather vague.

In the present work, atomically dispersed $\mathrm{Pt}$ catalyst is selectively synthesized via a simple wet-impregnation method on zeolite-templated carbon (ZTC) containing an extra-large amount (up to $17 \mathrm{wt} \%$ ) of sulfur. The abundant S-functionalities and unique carbon structure (that is, highly curved threedimensional networks of graphene nanoribbons) can stabilize a relatively high loading of $\mathrm{Pt}(5 \mathrm{wt} \%)$ in the form of atomically dispersed Pt. It is notable that, in earlier works ${ }^{11-17,19-24,27-31,41}$, atomically dispersed Pt (or noble metals) could be predominantly synthesized only at very low loadings $(<1 \mathrm{wt} \%)$ due to the small surface area of support materials as well as the lack of strong interaction between $\mathrm{Pt}$ and supports. In the oxygen reduction reaction (ORR) under an acidic environment, the catalyst does not follow the typical four-electron pathway producing $\mathrm{H}_{2} \mathrm{O}$, but predominantly produce $\mathrm{H}_{2} \mathrm{O}_{2}$ via a two-electron pathway without promoting consecutive $\mathrm{H}_{2} \mathrm{O}_{2}$ decomposition reactions. Consequently, the highly dispersed Pt catalyst including site isolated atoms holds promise for the production of the important fine chemical $\mathrm{H}_{2} \mathrm{O}_{2}$ by electrochemical means in fuel cells.

\section{Results}

Preparation of ZTCs. S-doped ZTCs were synthesized by chemical vapour deposition (CVD) of acetylene $/ \mathrm{H}_{2} \mathrm{~S}$ in $\mathrm{NaX}$ zeolite at $823 \mathrm{~K}$ (see details in the Methods section). Subsequently, the samples were heat-treated at $1,073 \mathrm{~K}$ under two different gas atmospheres, that is, $\mathrm{H}_{2} \mathrm{~S} / \mathrm{He}$ and pure $\mathrm{He}$. The former produced a carbon with a high S-content (HSC) and the latter produced a carbon with a low S-content (LSC). Dissolution of the zeolite template using an $\mathrm{HCl} / \mathrm{HF}$ solution produced self-standing microporous carbon materials. Purely carbonaceous ZTC was also synthesized by acetylene CVD without any $\mathrm{H}_{2} \mathrm{~S}$ flow for comparison $^{42}$. $\mathrm{N}_{2}$ adsorption-desorption isotherms and structural properties of the carbon materials are provided in Supplementary Fig. 1 and Supplementary Table 1. Briefly, all the carbon materials show large surface areas of $2,400-2,800 \mathrm{~m}^{2} \mathrm{~g}^{-1}$ and micropore volumes of $0.95-1.04 \mathrm{mlg}^{-1}$, indicating a faithful replication of the zeolite as a carbon framework ${ }^{42-44}$.

S-contents in HSC and LSC were determined by elemental analysis to be 17 and $4 \mathrm{wt} \%$, respectively. Energy dispersive $\mathrm{X}$-ray spectroscopy indicated that $\mathrm{S}$ atoms are uniformly distributed in the HSC and LSC particles (Fig. 1a). X-ray photoelectron spectroscopy (XPS) was used to study the chemical nature of the S-moieties (Fig. 1b). The results showed that the most dominant peaks are due to $\mathrm{C}-\mathrm{S}$ bonds $(163.8 \mathrm{eV}$ for $\left.2 p_{3 / 2}\right)$, while there are also some minor peaks corresponding to $\mathrm{S}-\mathrm{O}_{x}$ bonds $\left(166.1-168.4 \mathrm{eV}\right.$ for $\left.2 p_{3 / 2}\right)$. Physically deposited elemental sulfurs may also show peaks in a similar binding energy range with $\mathrm{C}-\mathrm{S}$ bonds, but their presence could be excluded. Namely, $\mathrm{CS}_{2}$ extraction did not decrease the S-contents of both samples ${ }^{45}$. The determination of the most dominant $\mathrm{S}$ species among the various moieties containing C-S bonds solely based on XPS is ambiguous (for example, sulfides, mercaptanes and thiophenes). However, considering

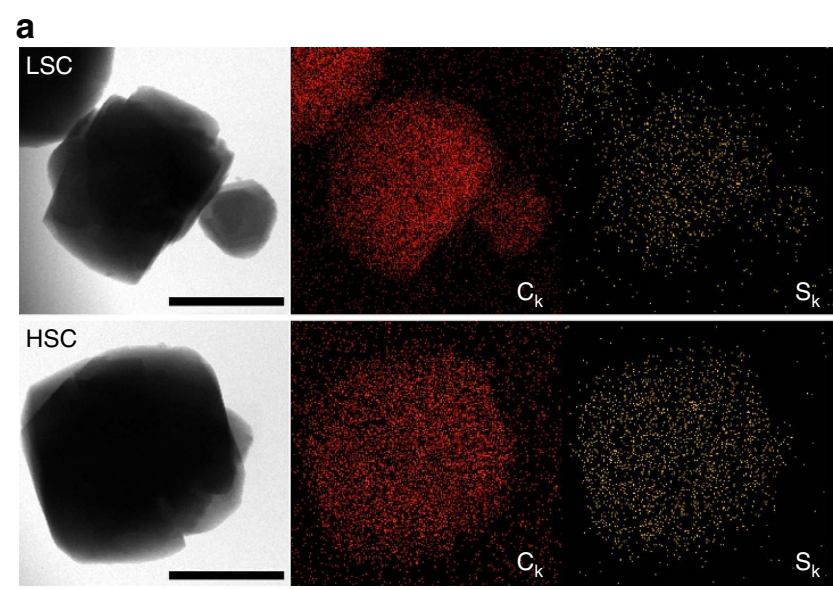

b

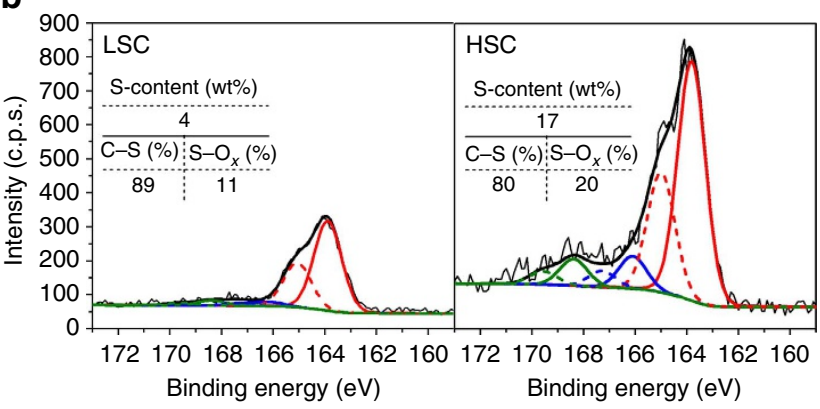

Figure 1 | Characterizations of LSC and HSC. (a) Energy dispersive X-ray mapping images of $C$ (red) and $S$ (yellow); scale bar, $1.0 \mu \mathrm{m}$. (b) XPS- $S_{2 p}$ spectra. XPS peaks were deconvoluted with $\mathrm{C}-\mathrm{S}$ (red lines) and $\mathrm{S}-\mathrm{O}_{x}$ (blue and green lines) phases by considering a spin-orbit splitting of $1.2 \mathrm{eV}$ in $2 p_{1 / 2}$ (dotted lines) and $2 p_{3 / 2}$ (solid lines). S-contents estimated from an elemental analysis and portions of S-phases determined from XPS peak deconvolution are summarized as an inset table. 
that the final heat-treatment temperature for the carbon synthesis was sufficiently high $(1,073 \mathrm{~K})$ for aliphatic sulfides and thiols to thermally decompose ${ }^{46}$, aromatic thiols and thiophenes are likely the prevailing functional groups on the carbon surface. To the best of our knowledge, the HSC sample is a carbon material simultaneously exhibiting the largest framework-sulfur content as well as surface area among various S-doped carbon materials reported to date ${ }^{47}$. This may be attributed to the unique structural features of ZTCs. It was previously proposed that the spatial constraint of zeolite micropores leads to the formation of buckybowl-like nanographenes linked into three-dimensional networks ${ }^{48}$, which provides a large number of graphene edge sites that can allow the incorporation of S-functional groups (Fig. $2 \mathrm{k}$ ).
Pt-supported ZTCs. Pt catalysts were synthesized by a conventional wet-impregnation of $\mathrm{H}_{2} \mathrm{PtCl}_{6}$ on the prepared carbon supports, followed by $\mathrm{H}_{2}$ reduction at $523 \mathrm{~K}$. Pt loadings of all the catalysts were found to be $5.0 \pm 0.2 \mathrm{wt} \%$. Bright-field transmission electron microscopy (TEM) images (Fig. 2a-c) show that $\mathrm{Pt}$ clusters having ca. 4-nm diameters are dispersed in Pt/ZTC (Fig. 2a), while 1-2-nm Pt clusters are present in Pt/LSC (Fig. 2b). In Pt/HSC (Fig. 2c), no Pt cluster is discernable in TEM. These results indicate that $\mathrm{Pt}$ dispersion increases as the S-content in the carbon framework increases. To further visualize sub-nanometre $\mathrm{Pt}$ species, atomic resolution high-angle annular dark-field scanning transmission electron microscopy (HAADF-STEM) was carried out (Fig. 2d-f) along with particle size distribution analysis (Fig. 2g-i). Consistent with the TEM study, Pt/ZTC
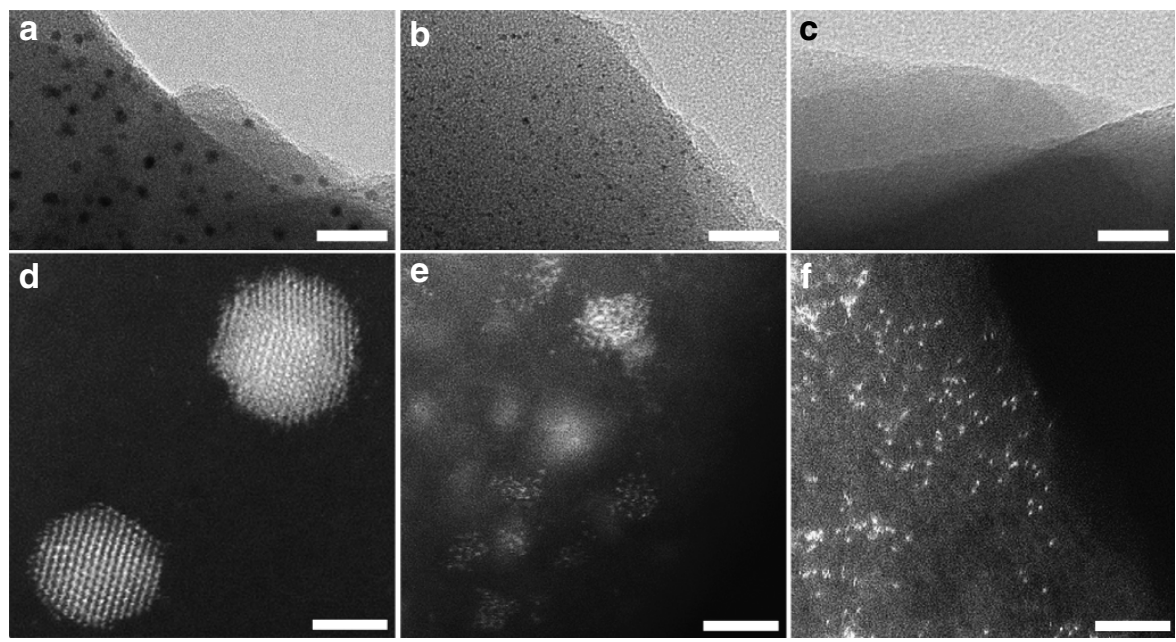

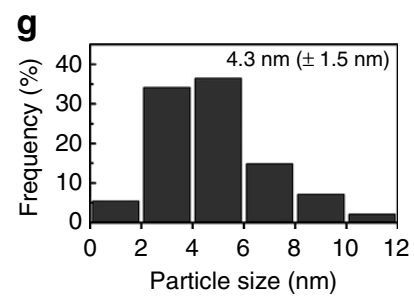

j

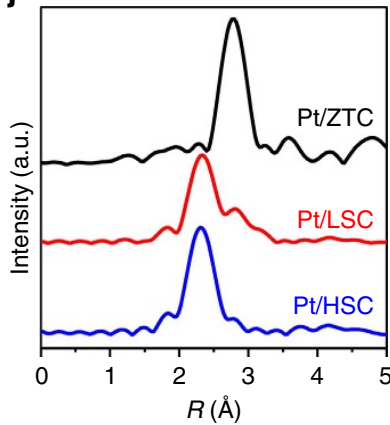

$\mathbf{h}$

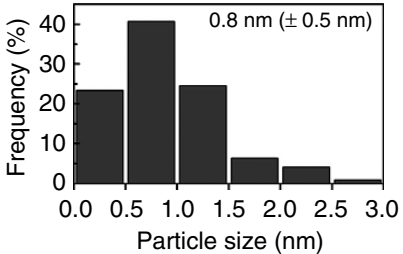

$\mathbf{k}$

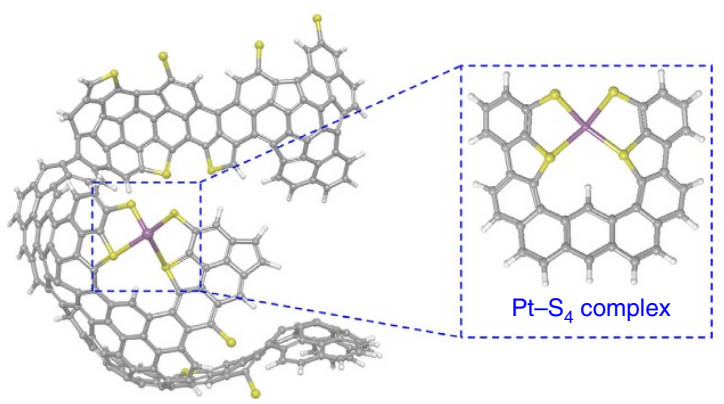

Figure 2 | Structures of the Pt species on the prepared catalysts. (a-c) TEM images indicating the presence of ca. 4-nm Pt clusters in Pt/ZTC (a), Pt clusters (1-2 nm) in Pt/LSC (b), and the absence of discernable Pt species in Pt/HSC (c); scale bar, $30 \mathrm{~nm}$. (d-f) To visualize the dispersion and structure of sub-nanometre Pt species, atomic resolution HAADF-STEM images are additionally provided for Pt/ZTC (d), Pt/LSC (e), and Pt/HSC (f); scale bar, $2 \mathrm{~nm}$. (g-i) Histograms of the particle size distributions for Pt/ZTC (g), Pt/LSC (h), and Pt/HSC (i). Average particle sizes and s.d.'s of Pt/ZTC and $\mathrm{Pt} / \mathrm{LSC}$ were fitted with a Gaussian function. The images reveal that Pt/LSC contains both of atomically dispersed Pt species and Pt clusters. Pt/HSC contains mainly the atomically dispersed Pt species. (j) Fourier transforms of $k^{3}$-weighted Pt LII-edge EXAFS, confirming that Pt species in Pt/HSC exhibit only Pt-S coordination ( $\mathrm{CN}=3.8$ ) without significant Pt-Pt coordination. ( $\mathbf{k}$ ) Proposed atomistic structure of the Pt/HSC based on the buckybowl-like structure of zeolite-templated carbon suggested by Nishihara et al. ${ }^{48}$ with possible thiophene- and thiolate-like functional groups at graphene edge sites, as well as coordinated Pt species (C: grey, $\mathrm{H}$ : white, S: yellow and Pt: purple). 
contains Pt clusters of a few nanometres in diameter (Fig. 2d). In Pt/LSC (Fig. 2e), atomically dispersed Pt species co-exist along with small Pt clusters $(<3 \mathrm{~nm})$. In Pt/HSC (Fig. 2f), Pt exists mainly as an atomically dispersed species without appreciable $\mathrm{Pt}$ clustering (more images are provided in Supplementary Fig. 2). The Pt/HSC showed imperceptible $\mathrm{H}_{2}$ chemisorption at $323 \mathrm{~K}$, supporting the negligible presence of $\mathrm{Pt}$ clusters on which $\mathrm{H}_{2}$ is dissociated and chemisorbed. We confirmed that $5 \mathrm{wt} \% \mathrm{Pt}$ is the maximum Pt loading allowing the selective synthesis of atomically dispersed $\mathrm{Pt}$ species even in HSC, and further increase of Pt loading above $5 \mathrm{wt} \%$ can also lead to the co-formation of Pt clusters. The atomically dispersed species are quite stable under the irradiation of highly energetic electron beam $(300 \mathrm{kV})$ and thus their dynamic motion could be recorded (Supplementary Movie 1). Thermal hopping of Pt to nearby sites was observed, but Pt sintering was not observed within the time scale of our investigation $(\sim 5 \mathrm{~min})$. The Pt species were also stable under ambient conditions for over a year (Supplementary Fig. 3), indicating that the S-moieties on the carbon support efficiently stabilize them.

Extended X-ray absorption fine structure (EXAFS) was used to analyse the chemical nature of the Pt species (Fig. 2j). EXAFS fitting of the Pt/ZTC shows a dominant peak at $2.75 \AA$ corresponding to the $\mathrm{Pt}-\mathrm{Pt}$ coordination with a coordination number (CN) of 9.2 (Supplementary Table 2). In clear contrast, $\mathrm{Pt} / \mathrm{HSC}$ shows a dominant peak at $2.29 \AA$, which can be assigned to $\mathrm{Pt}-\mathrm{S}$ coordination $(\mathrm{CN}=3.8)$. No appreciable $\mathrm{Pt}-\mathrm{Pt}$ coordination was detected. These results support that $\mathrm{Pt}$ is dominantly present as an atomically dispersed Pt ligated by approximately four S-moieties. Pt/LSC shows intermediate behaviour with both $\mathrm{Pt}-\mathrm{Pt}(\mathrm{CN}=3.3)$ and $\mathrm{Pt}-\mathrm{S}$ coordinations $(\mathrm{CN}=2.4)$. XPS-Pt (Supplementary Fig. 4) analysis revealed that the fraction of $\mathrm{Pt}^{2+}$ becomes more dominant as the S-content of the carbon support increases: $\mathrm{Pt} / \mathrm{ZTC}, \mathrm{Pt} / \mathrm{LSC}$ and $\mathrm{Pt} / \mathrm{HSC}$ show percentage ratios of 73.3/12.3/14.4, 40.3/49.1/10.6 and $0 / 100 / 0$ for $\mathrm{Pt}^{0} / \mathrm{Pt}^{2+} / \mathrm{Pt}^{4+}$, respectively. Thus, it can be concluded that the atomically dispersed $\mathrm{Pt}$ species have an oxidation state of $\mathrm{Pt}^{2+}$, while $\mathrm{Pt} / \mathrm{ZTC}$ and $\mathrm{Pt} / \mathrm{LSC}$ have significant portions of $\mathrm{Pt}^{0}$. $\mathrm{X}$-ray absorption near-edge structure (XANES) (Supplementary Figs 5-7; Supplementary Table 3) also showed that the white line intensity and position $\left(E_{0}\right)$ gradually increased in the order of ZTC $<$ LSC $<$ HSC, confirming that more oxidized Pt species present on support with higher S-content. The white line intensity of Pt/HSC exactly corresponds to that of $\mathrm{Pt}^{2+}$ (Supplementary Fig. 8) ${ }^{49}$. In earlier works in the literature ${ }^{9,14,16,22,29}$, the oxidation state of atomically dispersed $\mathrm{Pt}$ was found to vary between +2 and +4 depending on the type of support.

In the Pt/HSC, it is remarkable that the S-moieties fixed in the solid carbon framework can form a four-coordinated mononuclear Pt complex similar to the homogeneous organometallic Pt complexes ligated with molecular ligand $s^{50}$. It appears that the unique structure of the ZTC, that is, curved threedimensional networks of graphene nanoribbons, allows the formation of highly S-coordinated Pt structures (Fig. 2k). It was previously reported that the ZTCs are also physically flexible due to their unique structure ${ }^{51}$, which may allow local geometrical optimization of the carbon framework for effective Pt coordination. To confirm the importance of the carbon microstructure on the S-content and the formation of atomically dispersed $\mathrm{Pt}$, we synthesized a mesoporous S-doped carbon using mesoporous SBA-15 as a template, and similarly supported $5 \mathrm{wt} \% \mathrm{Pt}$. The material showed only $7 \mathrm{wt} \%$ S-content and the dominant presence of Pt clusters (Supplementary Fig. 9). This indicates that the unique carbon structure of ZTC plays a decisive role for efficient doping of $S$ and consequent stabilization of atomically dispersed Pt.
Oxygen reduction reaction. The ORR behaviour was investigated in an $\mathrm{O}_{2}$-saturated $0.1 \mathrm{M} \mathrm{HClO}_{4}$ electrolyte (Fig. 3a; see details in Supplementary Figs 10 and 11 and Supplementary Note 1). Pt/ZTC and Pt/LSC show onset potentials (potential at $-1 \mu \mathrm{A} \mathrm{cm}^{-2}$ ) of 0.99 and $0.95 V_{\mathrm{RHE}}$, respectively, which are comparable to those of typical $\mathrm{Pt}$ electrocatalysts that mainly produce $\mathrm{H}_{2} \mathrm{O}$ via a four-electron pathway $\left(E^{\circ}{ }_{\mathrm{O} 2 / \mathrm{H} 2 \mathrm{O}}=1.23\right.$ $\left.V_{\mathrm{SHE}}\right)^{52,53}$. In contrast, Pt/HSC reveals an onset potential of 0.71 $V_{\mathrm{RHE}}$, close to the thermodynamic potential of $\mathrm{H}_{2} \mathrm{O}_{2}$ production $\left(E_{\mathrm{O} 2 / \mathrm{H} 2 \mathrm{O} 2}^{\circ}=0.69 V_{\mathrm{SHE}}\right)$. Rotating ring disk electrode (RRDE) experiments (Fig. $3 \mathrm{~b}$ ) revealed that $\mathrm{Pt} / \mathrm{HSC}$ produces $\mathrm{H}_{2} \mathrm{O}_{2}$ with up to $96 \%$ selectivity, while Pt/ZTC and Pt/LSC exhibit $\mathrm{H}_{2} \mathrm{O}_{2}$ production selectivities lower than 28 and $60 \%$, respectively. This indicates that $\mathrm{Pt} / \mathrm{HSC}$ catalyses the ORR reaction predominately through a two-electron pathway $(n=2.1)$, whereas Pt/ZTC $(n=3.5)$ and Pt/LSC $(n=2.9)$ enable mixed two- and fourelectron pathways. The results are consistent with the previous report by Anderson's group ${ }^{54}$, where size-selected $\mathrm{Pt}_{n}$ clusters deposited on indium tin oxide were used as an ORR catalyst. The materials showed increased $\mathrm{H}_{2} \mathrm{O}_{2}$ selectivity as the $\mathrm{Pt}_{n}$ cluster size decreased, and a maximized $\mathrm{H}_{2} \mathrm{O}_{2}$ selectivity was observed with the smallest $\mathrm{Pt}_{1}$ species. Very recently, Lee and colleagues also reported that supporting $0.35 \mathrm{wt} \% \mathrm{Pt}$ on $\mathrm{TiN}$ led to the formation of atomically dispersed $\mathrm{Pt}$ as well as a small amount of $\mathrm{Pt}$ clusters ${ }^{41}$, which showed $\mathrm{H}_{2} \mathrm{O}_{2}$ selectivity of $65 \%$. They also mentioned that $\mathrm{H}_{2} \mathrm{O}_{2}$ selectivity can reach $90 \%$, if the Pt loading decreases to $0.1 \mathrm{wt} \%$ where the $\mathrm{Pt}$ cluster formation is further suppressed.

The kinetics of consecutive $\mathrm{H}_{2} \mathrm{O}_{2}$ decomposition via a peroxide disproportionation reaction ( $\mathrm{PDR}, \mathrm{H}_{2} \mathrm{O}_{2(\mathrm{aq})} \rightarrow \mathrm{H}_{2} \mathrm{O}_{(\mathrm{l})}+0.5 \mathrm{O}_{2(\mathrm{~g})}$ ) and peroxide reduction reaction $\left(\mathrm{PRR}, \mathrm{H}_{2} \mathrm{O}_{2(\mathrm{aq})}+2 \mathrm{H}^{+}{ }_{(\mathrm{aq})}+\right.$ $\left.2 \mathrm{e}^{-} \rightarrow 2 \mathrm{H}_{2} \mathrm{O}_{(1)}\right)$ on $\mathrm{Pt}$ is expected to be so fast that no $\mathrm{H}_{2} \mathrm{O}_{2}$ escapes from its surface ${ }^{55}$, which in turn suggests that the high yield of $\mathrm{H}_{2} \mathrm{O}_{2}$ could indeed be due to the unique characteristics of the $\mathrm{Pt} / \mathrm{HSC}$. However, in the presence of site-blocking spectator species and low Pt-content, $\mathrm{H}_{2} \mathrm{O}_{2}$ diffusion into the bulk of the electrolyte could be artificially favoured compared with its subsequent decomposition in the RRDE experiments ${ }^{56}$. To rule out an artificial origin of the high $\mathrm{H}_{2} \mathrm{O}_{2}$ yield on Pt/HSC, the suppressions of PDR and PRR are separately investigated with $10 \mathrm{mM} \mathrm{H}_{2} \mathrm{O}_{2}$ solutions. While Pt/ZTC and Pt/LSC induce a fast decrease in $\mathrm{H}_{2} \mathrm{O}_{2}$ concentrations when $10 \mathrm{mg}$ samples are dispersed in the solution, the PDR activity (Fig. 3c) is inhibited on $\mathrm{Pt} / \mathrm{HSC}$. Furthermore, Pt/HSC shows significantly larger overpotential and lower reduction currents for the PRR than the other samples (Fig. 3d), confirming that the unique ORR behaviour of the Pt/HSC is not an artefact. To elucidate the catalytic active site of Pt/HSC, ORR on Pt-free HSC and on $\mathrm{Pt} / \mathrm{HSC}$ under $\mathrm{CN}^{-}$poisoning is additionally studied (Supplementary Fig. 12). Pt-free HSC exhibits a much larger overpotential than that of $\mathrm{Pt} / \mathrm{HSC}$, and its ORR performance is not significantly affected by $\mathrm{CN}^{-}$poisoning. In contrast, the ORR activity on Pt/HSC is significantly decreased after $\mathrm{CN}^{-}$poisoning due to the blockage of the active $\mathrm{Pt}$ sites. These results support that ORR on Pt/HSC is indeed catalysed by the atomically dispersed Pt species.

To confirm the concept of selective $\mathrm{H}_{2} \mathrm{O}_{2}$ production in a fuel cell via single-site electrocatalysis, an electrochemical $\mathrm{H}$-cell was employed as a first prototype reactor (Fig. 3e). Pt/HSC showed $97.5 \mu \mathrm{mol} \mathrm{h}^{-1} \mathrm{~cm}^{-2} \mathrm{H}_{2} \mathrm{O}_{2}$ production rate during the initial $1 \mathrm{~h}$ under short-circuit operation $(V=0)$, while Pt/ZTC and Pt/LSC exhibited production rates of $\sim 0$ and $5.3 \mu \mathrm{molh}^{-1} \mathrm{~cm}^{-2}$, respectively. In total, the concentrations of $\mathrm{H}_{2} \mathrm{O}_{2}$ produced on the Pt/ZTC and Pt/LSC were $<7 \mathrm{mM}$ in a catholyte $(5 \mathrm{ml})$ after $6 \mathrm{~h}$ operation, while the concentration reached up to $160 \mathrm{mM}$ with $\mathrm{Pt} / \mathrm{HSC}$. Pt/HSC shows stable catalytic performance as 
a

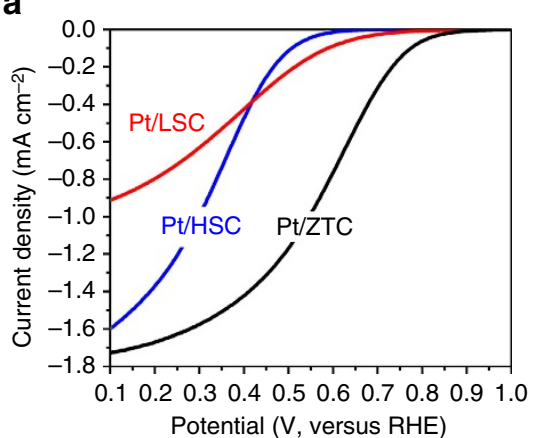

C
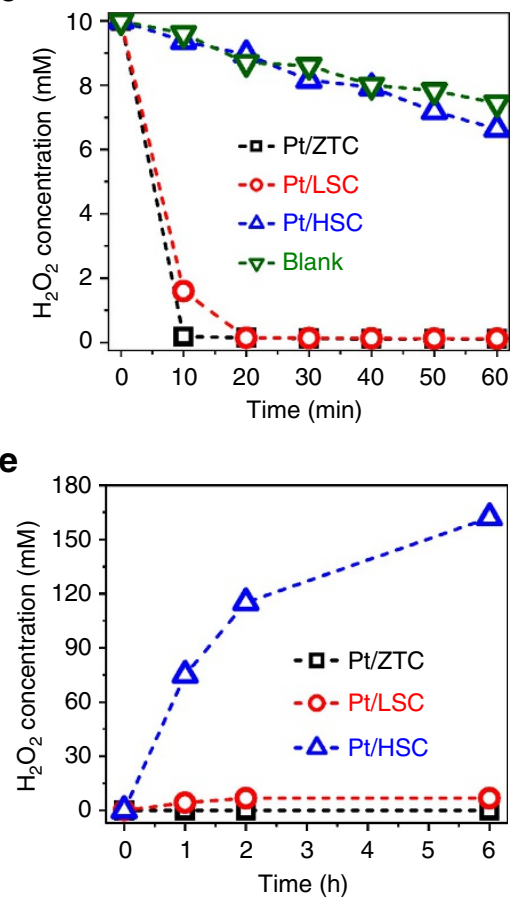

b

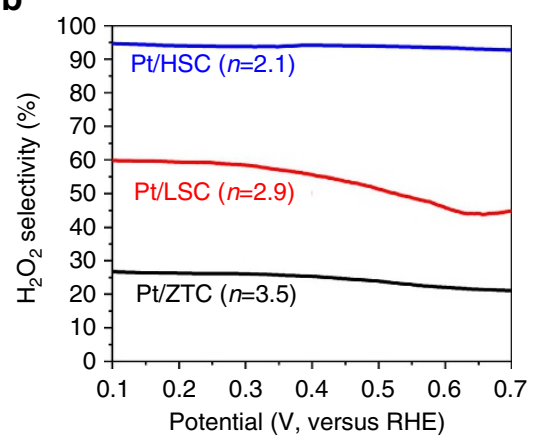

d

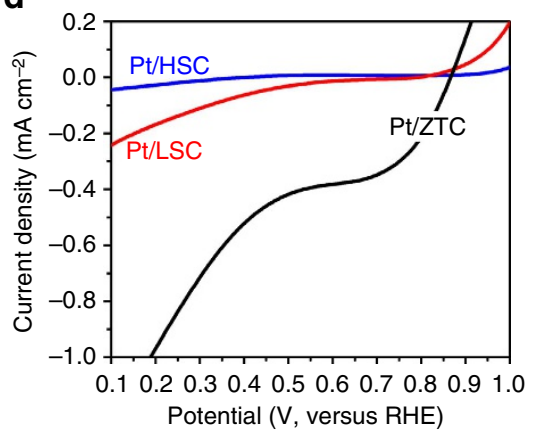

f

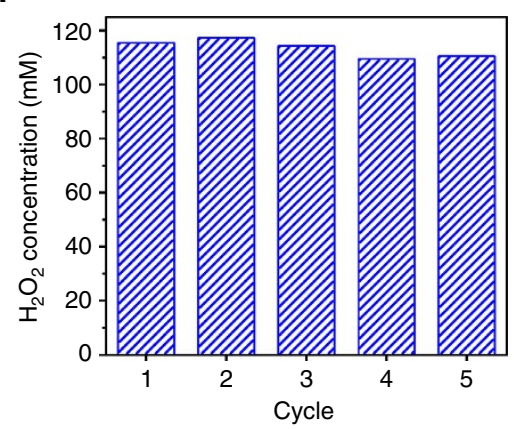

Figure 3 | Electrocatalytic properties. (a) ORR activities of the prepared catalysts measured in an $\mathrm{O}_{2}$-saturated $0.1 \mathrm{M} \mathrm{HClO}_{4}$ electrolyte with 900 r.p.m. rotation. (b) $\mathrm{H}_{2} \mathrm{O}_{2}$ production selectivity estimated by RRDE experiments (Pt ring potential: $1.2 \mathrm{~V}_{\mathrm{RHE}}$ ). (c) PDR activities derived from the decline in $\mathrm{H}_{2} \mathrm{O}_{2}$ concentration in a $10 \mathrm{mM} \mathrm{H}_{2} \mathrm{O}_{2}$ starting solution $(50 \mathrm{ml}$ ) containing $10 \mathrm{mg}$ catalysts. For comparison, the PDR of a blank solution without catalyst was also investigated. (d) $\mathrm{PRR}$ activities measured in a $10 \mathrm{mM} \mathrm{H}_{2} \mathrm{O}_{2} / 0.1 \mathrm{M} \mathrm{HClO}_{4}$ electrolyte with 900 r.p.m. rotation. (e) Accumulated $\mathrm{H}_{2} \mathrm{O}_{2}$ concentrations in an $\mathrm{H}$-cell with a $1 \mathrm{M} \mathrm{HClO}_{4}$ electrolyte and a Nafion 115 membrane. The $\mathrm{H}$-cell was operated in short-circuit condition $(\mathrm{V}=0)$ at $278 \mathrm{~K}$. (f) $\mathrm{Concentrations} \mathrm{of}$ $\mathrm{H}_{2} \mathrm{O}_{2}$ produced on the $\mathrm{Pt} / \mathrm{HSC}$ in an electrochemical $\mathrm{H}$-cell during repeated $2 \mathrm{~h}$ operation cycles. Concentrations of $\mathrm{H}_{2} \mathrm{O}_{2}$ are evaluated by iodometry.

confirmed by the repeated $2 \mathrm{~h}$ operation cycles (Fig. 3f). HAADFSTEM micrographs of the Pt/HSC after the operation indicate that most of the atomically dispersed Pt species are preserved after the operation (Supplementary Fig. 13).

Active site characterization and theoretical calculations. To elucidate the active site structure in Pt/HSC, energy minimization for the three proposed $\mathrm{Pt}-\mathrm{S}_{4}$ model structures was carried out via density functional theory (DFT) using Perdew-Burke-Ernzerhof functional ${ }^{57}$ coupled with semiempirical dispersion correction ${ }^{58}$ (Supplementary Fig. 14). The three models include (1) Pt ligated by two thiophenes and two thiolates, (2) Pt ligated by one thiophene, one thiol and two thiolates, and (3) Pt ligated by two thiols and two thiolates. Because the oxidation state of $\mathrm{Pt}$ was confirmed to be +2 by XPS and XANES, two anionic thiolate ligands $\left(-\mathrm{S}^{-}\right)$were expected to exist within Pt/HSC for chargebalancing. The three model structures were used for multi-shell fitting of the EXAFS (Supplementary Figs 15-17). The results showed that the first model structure gave the best fitting $(\mathrm{R}$-factor $=0.0053)$ over the other two model structures (R-factors $=0.0122$ and 0.0138). Thus, DFT calculations were carried out using the first model structure (Fig. $2 \mathrm{k}$ ) to understand the ORR mechanism.

Since $\mathrm{Pt}^{2}+$ has a typical $d^{8}$ electron configuration, the $\mathrm{Pt}-\mathrm{S}_{4}$ complex forms a square-planar-type ligand arrangement (Fig. 4a). When it is solvated with water, it is found that the $\mathrm{Pt}^{2+}$ centre can favourably interact with two water molecules, while losing its interactions with two sulfur atoms of thiophene moieties $(0.63 \mathrm{eV}$ downhill; Fig. 4b). This is attributed to the stronger Lewis basicity of the oxygen lone pairs compared with that of the sulfur lone pairs in thiophene. This leads to a distorted Pt centre located out of the original square planar geometry, leading $\mathrm{Pt}$ to be more suitable for catalytic actions via ligand substitutions. By substituting one of the water molecules, the Pt centre then can reduce $\mathrm{O}_{2}$ via a series of proton-coupled electron transfers $\left(\right.$ PCETs) ${ }^{59}$. DFT energetics suggests that the first PCET (Fig. $4 \mathrm{c}$ ) is the potential-determining step $^{60}$ in both the two- and 


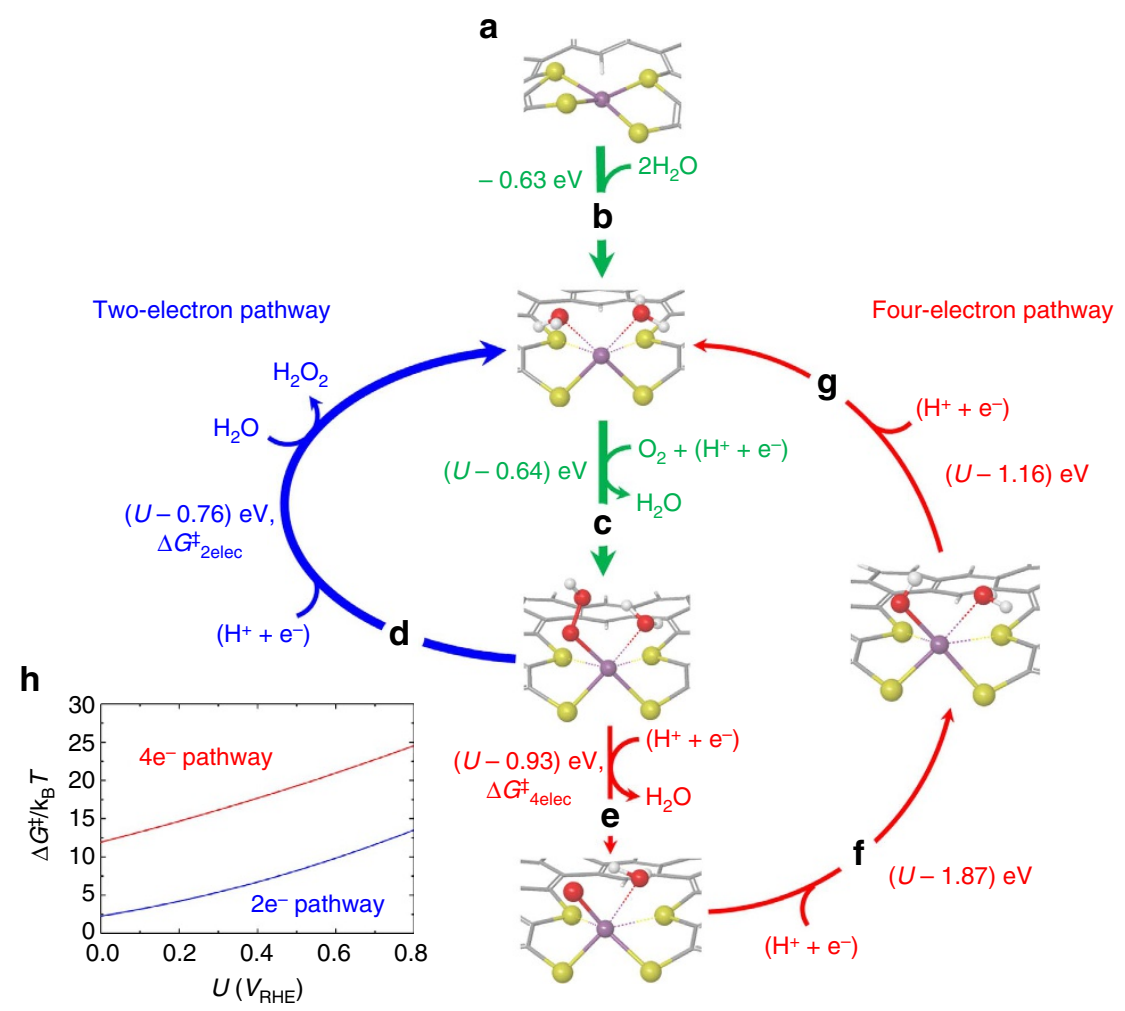

Figure 4 | Proposed ORR mechanism on the atomically dispersed Pt catalyst. (a) Atomically dispersed Pt (purple) complexed with four sulfur-containing moieties consisting of two thiophene and two thiolate groups that are covalently bonded to a carbon framework. (b) Activation of Pt centre by substituting two $\mathrm{S}$ of thiophene-like moieties with two $\mathrm{O}$ of water molecules. (c) The first reduction of an $\mathrm{O}_{2}$ via proton-coupled electron transfer (PCET), forming OOH. This is a shared elementary step of the two- and four-electon pathways. (d) Two-electron pathway: $\mathrm{H}_{2} \mathrm{O}_{2}$ formation by the second PCET and the subsequent substitution of an $\mathrm{H}_{2} \mathrm{O}_{2}$ molecule with an outer-sphere $\mathrm{H}_{2} \mathrm{O}$ molecule, recovering the initial state where Pt is complexed with two thiolates and two waters. (e) Four-electron pathway: $\mathrm{H}_{2} \mathrm{O}$ formation by the second PCET involving O-O bond dissociation. (f) Four-electron pathway: $\mathrm{OH}$ formation by the third PCET to the $\mathrm{O}$ atom. (g) The fourth PCET to the $\mathrm{OH}$ forms an inner-sphere $\mathrm{H}_{2} \mathrm{O}$, recovering the initial state where Pt is complexed with two thiolates and two waters. (h) Calculated kinetic barriers of the second PCET steps for the two-electron pathway (blue) and the four-electron pathway (red) using Marcus kinetic theory. (C: grey, H: white, S: yellow, O: red, and Pt: purple).

four-electron pathways, where the calculated ORR limiting potential is $0.64 V_{\mathrm{RHE}}$, which relatively well matches with the experimental onset potential of $0.71 V_{\mathrm{RHE}}$ considering the inherent error range of DFT energies and the simplicity of the model system.

This implies that all elementary steps of the four-electron pathway become thermodynamically favourable under the bias potential of $U \leq 0.64 V_{\mathrm{RHE}}$, and thereby the experimentally observed high chemoselectivity towards the two-electron pathway cannot be rationalized. Moreover, the competing step of the second PCET reaction towards the four-electron pathway (Fig. 4e) is thermodynamically even more favourable than that towards the two-electron pathway (Fig. $4 \mathrm{~d}$ ). The results indicate that electrocatalysis on atomically dispersed Pt catalyst is not controlled by thermodynamics, but rather is controlled by kinetics. We thus calculated the kinetic barriers required for the second PCETs using the Marcus theory. By taking the number of transferred proton-electron pair as a reaction coordinate for PCET, Marcus parabolas were constructed and the reorganization energies of $\lambda_{\mathrm{o}}$ were calculated (Supplementary Fig. 18). Then, the kinetic barrier of each pathway, $\Delta G^{\ddagger}$ was calculated as a function of bias potential of $U$, using the Marcus theory:

$$
\Delta G^{\ddagger}=\frac{\left(\lambda_{\mathrm{o}}+\Delta G^{0}+U\right)^{2}}{4 \lambda_{\mathrm{o}}}
$$

where $\Delta G^{0}$ is the Gibbs free energy of reaction with no bias potential. As shown in Fig. 4h, within considered potential range of $U<0.8 V_{\mathrm{RHE}}$, it is found that the two-electron pathway is always kinetically more favoured than the four-electron pathway. The main difference between the kinetics of the two- and fourelectron pathways originates from the different $\lambda_{\mathrm{o}}$ values; $\lambda_{\mathrm{o}}$ of the two-electron pathway is only $0.55 \mathrm{eV}$, while $\lambda_{\mathrm{o}}$ of the fourelectron pathway is $1.84 \mathrm{eV}$. The larger $\lambda_{\mathrm{o}}$ of the four-electron pathway is attributed to its second PCET accompanying a significant reorganization process for breaking the $\mathrm{O}-\mathrm{O}$ bond.

Furthermore, the thermodynamic cost to bind $\mathrm{H}_{2} \mathrm{O}_{2}$ molecule to the Pt catalytic active centre is substantial; $0.41 \mathrm{eV}$ uphill to bind one $\mathrm{H}_{2} \mathrm{O}_{2}$ molecule for PRR, and another $0.33 \mathrm{eV}$ uphill to bind the second $\mathrm{H}_{2} \mathrm{O}_{2}$ molecule for PDR (Supplementary Fig. 19). This explains our experimental observation that the atomically dispersed $\mathrm{Pt}$ catalyst is almost inactive in decomposing $\mathrm{H}_{2} \mathrm{O}_{2}$.

\section{Discussion}

We have synthesized a sulfur-doped ZTC (HSC), which exhibits extra-large S-content (17 wt\% S) and surface area $\left(\sim 2,800 \mathrm{~m}^{2} \mathrm{~g}^{-1}\right)$. The novel carbon material stabilizes a relatively high loading of $\mathrm{Pt}$ (up to $5 \mathrm{wt} \%$ ) in the form of atomically dispersed Pt. Its electrochemical behaviour significantly differs from that of cluster-type Pt catalysts: the atomically dispersed Pt catalyst selectively catalyse a two-electron ORR pathway producing $\mathrm{H}_{2} \mathrm{O}_{2}$, rather than the conventional fourelectron ORR pathway producing $\mathrm{H}_{2} \mathrm{O}$. Consequently, the catalyst can be considered as a promising approach for the production of $\mathrm{H}_{2} \mathrm{O}_{2}$, while at the same time generating electricity 
as a by-product of fuel cells. Moreover, the extraordinary electrochemical properties of the atomically dispersed Pt catalyst, demonstrated here for one sample reaction only, might be considered as a model for other important systems. As the abundant S-functionality in HSC allows the synthesis of various atomically dispersed metal catalysts other than $\mathrm{Pt}$, it can provide wide material opportunities for studying unique catalytic behaviours in diverse electrochemical reactions.

\section{Methods}

Chemicals. All gases used in this study were supplied from Chungang Industrial Gases (Korea). $\mathrm{H}_{2} \mathrm{PtCl}_{6}-5.5 \mathrm{H}_{2} \mathrm{O}$ was purchased from Kojima Chemicals (Japan). $\mathrm{HClO}_{4}, \mathrm{KCN}, \mathrm{CS}_{2}$, starch solution $\left(1 \%\right.$ in $\left.\mathrm{H}_{2} \mathrm{O}\right), \mathrm{Na}_{2} \mathrm{~S}_{2} \mathrm{O}_{3}$ and $\mathrm{NaX}$ zeolite were purchased from Sigma-Aldrich (USA). KI was supplied from Junsei Chemicals (Japan). $\mathrm{H}_{2} \mathrm{O}_{2}$ (30 wt\%) and $\mathrm{HCl}(35 \mathrm{wt} \%)$ solutions were purchased from Daejung chemicals (Korea). HF (49 wt\%) was supplied from J.T. Baker (USA).

Preparation of catalysts. S-doped ZTCs were synthesized by CVD of acetylene/ $\mathrm{H}_{2} \mathrm{~S}$ mixed gas on $\mathrm{NaX}$ zeolite at $823 \mathrm{~K}$. In a typical synthesis, $5 \mathrm{~g}$ NaX zeolite was loaded in a quartz plug-flow reactor. The reactor was heated to $823 \mathrm{~K}^{\left(2 \mathrm{~K} \mathrm{~min}^{-1}\right.}$ ramp) under $200 \mathrm{ml} \mathrm{min}^{-1} \mathrm{He}$ flow. At the target temperature, $280 \mathrm{ml} \mathrm{min}^{-1}$ acetylene $/ \mathrm{H}_{2} \mathrm{~S}(1.4 / 1.4 \%$ in $\mathrm{He})$ mixed gas was introduced into the reactor for $24 \mathrm{~h}$. After CVD, the samples were heat-treated at $1,073 \mathrm{~K}\left(2 \mathrm{~K} \mathrm{~min}^{-1} \mathrm{ramp}\right)$ for $3 \mathrm{~h}$ under two different gas atmospheres: $80 \mathrm{ml} \mathrm{min}^{-1} 5 \% \mathrm{H}_{2} \mathrm{~S} / \mathrm{He}$ and pure He were flowed to produce carbons with HSC and LSC, respectively. For comparison, purely carbonaceous ZTC was similarly synthesized by acetylene CVD, but without $\mathrm{H}_{2} \mathrm{~S}$ flow. After cooling to room temperature, the resulting samples were etched with $800 \mathrm{ml}$ of an $\mathrm{HCl} / \mathrm{HF}(1.1 / 0.8 \mathrm{wt} \%)$ aqueous solution twice to remove the zeolite template. After filtration and thorough washing with deionized water, the samples were dried at $373 \mathrm{~K}$. Pt was supported on the prepared carbons by a conventional wet-impregnation method, followed by $\mathrm{H}_{2}$ reduction. Typically, $0.3 \mathrm{~g}$ carbon was dispersed in $100 \mathrm{ml}$ deionized water containing $0.04 \mathrm{~g}$ of $\mathrm{H}_{2} \mathrm{PtCl}_{6}-5.5 \mathrm{H}_{2} \mathrm{O}(5 \mathrm{wt} \% \mathrm{Pt}$ loading). The water was evaporated at $353 \mathrm{~K}$ under $300 \mathrm{mbar}$. The resultant powder was further dried overnight in an oven at $353 \mathrm{~K}$, and subsequently reduced at $523 \mathrm{~K}$ for $3 \mathrm{~h}$ under a $200 \mathrm{ml} \mathrm{min}^{-1} \mathrm{H}_{2}$ flow.

Physical characterizations. $\mathrm{N}_{2}$ adsorption-desorption isotherms were measured using a BEL-sorp-max (BEL Japan) volumetric analyser at $77 \mathrm{~K}$. Before each measurement, all samples were degassed at $473 \mathrm{~K}$ for $4 \mathrm{~h}$, and the specific areas were determined in the $P / P_{0}$ range of $0.05-0.15$ using a Brunauer-Emmett-Teller equation. The elemental analysis was conducted with a FLASH 2,000 series (Thermo Scientific). The inductively coupled plasma optical emission spectroscopy (ICP-OES) was carried out using an ICP-OES 720 (Agilent) after sample pretreatment at $473 \mathrm{~K}$ in a concentrated $\mathrm{HNO}_{3} / \mathrm{HCl}$ mixture (7:3). TEM and energy dispersive X-ray images were taken using a JEM2100-F (Jeol Ltd) operated at $200 \mathrm{kV}$ accelerating voltage. HAADF-STEM analysis was performed using a FEI Titan cubed G2 60-300 microscope operating at $300 \mathrm{kV}$ (Kaist Analysis centre for Research Advancement, KARA). The samples were prepared by drop casting and drying onto a lacey carbon grid. HRSTEM Z-Contrast conditions were achieved using a probe semi-angle of $19.3 \mathrm{mrad}$ and an inner collection angle of the detector of $40 \mathrm{mrad}$. The Pt particle size distributions were analysed using an ImageJ software by counting at least $500 \mathrm{Pt}$ species, and the average particle sizes and s.d.'s were fitted using a Gaussian function. $\mathrm{H}_{2}$ chemisorption isotherms was measured with ASAP2020 (Micromeritics) adsorption volumetric analyser. $\mathrm{H}_{2}$ (99.999\%) gas was used as received. Before adsorption measurement, all the samples were re-reduced at $523 \mathrm{~K}$ flowing $\mathrm{H}_{2}\left(50 \mathrm{ml} \mathrm{min}^{-1}\right)$ for $2 \mathrm{~h}$, followed by evacuation for $2 \mathrm{~h}$ at the same temperature. Adsorption measurements were carried out at $323 \mathrm{~K}$ in the pressure range of $0.3-60 \mathrm{kPa}$. The chemisorption amounts were determined by extrapolation of the high-pressure linear portion $(7-28 \mathrm{kPa})$ of the isotherm to zero pressure. XPS was carried out using Sigma Probe (Thermo VG Scientific) equipped with a microfocused monochromator X-ray source. XPS-S $2 p$ and $-\mathrm{Pt}_{4 f}$ peaks were deconvoluted with $1: 2$ and $3: 4$ of spin-orbit splitting ratios $(\Delta=1.2 \mathrm{eV}$ for $\mathrm{S}_{2 p}$ and $3.33 \mathrm{eV}$ for $\mathrm{Pt}_{4 f}$ ), respectively ${ }^{61}$. The binding energies used for the peak deconvolution of XPS-S spectra (for $2 p_{3 / 2}$ ) were $163.8 \mathrm{eV}$ for the $\mathrm{C}-\mathrm{S}$ and $166.1 / 168.4 \mathrm{eV}$ for the $\mathrm{S}-\mathrm{O}_{x}$ species, respectively. The binding energies used for the peak deconvolution of the XPS-Pt spectra (for $4 f_{7 / 2}$ ) were $71.2 \mathrm{eV}$ for $\mathrm{Pt}^{0}, 72.2 \mathrm{eV}$ for $\mathrm{Pt}^{2+}$ and $73.5 \mathrm{eV}$ for $\mathrm{Pt}^{4+}$, respectively.

XAFS investigations. X-ray absorption fine spectroscopy (XAFS) data of the prepared catalysts over $\mathrm{Pt}_{\mathrm{III}}$-edge $(11,570 \mathrm{eV})$ were collected in transmission mode using ionization detectors (Oxford) at the Pohang Accelerator Laboratory (7D-XAFS beamline). The beam energy and ring current were $2.5 \mathrm{GeV}$ and $200 \mathrm{~mA}$, respectively. The step and duration time for XANES and EXAFS were $0.3 \mathrm{eV}$ and $2 \mathrm{~s}$, and $0.03 \AA^{-1}$ and $3 \mathrm{~s}$, respectively. For XAFS measurement, $0.1 \mathrm{~g}$ catalysts were mounted in a sample holder $\left(w \times l \times d=3 \times 8 \times 2 \mathrm{~mm}^{3}\right)$. The XAFS data were calibrated using a Pt foil before and after the measurement to guarantee no shift in edge energy. The XANES data were analysed using Athena implemented in Demeter program package (0.9.23). In the fitting, the height for the arctangent function corresponding to the transition to continuum level was fixed to one to maintain the consistency in the analysis. For EXAFS analysis, Artemis also implemented in Demeter program package $(0.9 .23)$ was utilized after the data processing using Athena. The background removal was performed to extract EXAFS signal using AUTOBK program for $R_{\mathrm{bkg}}=1 \AA$. The extracted EXAFS data in $k$ space was Fourier transformed with the Kaiser-Bessel window function, $1 \AA^{-}$ after $k^{3}$-weighting. Phase shifts and amplitude functions of the reference were generated using Feff 6L. The number of independent points of the data for the curve fit, $N_{\text {idp }}$, determined from Nyquist theorem, was always larger than the number of variables, providing a sufficient degree of freedom, $N_{\mathrm{var}}$. The scattering path from the possible model structure was obtained from the Feff calculation. Only scattering with large contribution was included in the multi-shell fitting. The many-body reduction factor $\left(S_{0}^{2}\right)$ for Pt was determined as 0.82 from the curve fit of the EXAFS of Pt foil. The statistical quality of the curve fit with the proposed models can be determined from the $R$-factor and the $\chi^{2}$ function available in the refinement.

Electrochemical measurements. Electrochemical properties were characterized using VMP3 (Bio-Logic) in a three-electrode beaker cell equipped with a Pt wire counter electrode (ALS Co, 002233) and an Ag/AgCl reference electrode (ALS Co, 012167). Unless it is specially mentioned, $0.1 \mathrm{M} \mathrm{HClO}_{4}$ solution was used as an electrolyte. Before the electrochemical experiments, the $\mathrm{Ag} / \mathrm{AgCl}$ reference electrode was calibrated in $0.1 \mathrm{M} \mathrm{HClO}_{4}$ electrolyte and potentials were converted to reversible hydrogen electrode (RHE) scale $\left(V_{\mathrm{RHE}}=V_{\mathrm{Ag} / \mathrm{AgCl}}+0.287 \mathrm{~V}\right)$.

The ORR was measured using RRDE-3A (ALS Co) as a rotator and a ring disk electrode (A-011162, ALS Co) as a working electrode. The catalyst ink was prepared by dispersing $5 \mathrm{mg}$ catalysts in Nafion solution $(6.5 \mathrm{ml}$, Nafion/ catalyst $=10 \%)$. The working electrode was prepared by dropping the catalyst ink $(8.2 \mu \mathrm{l})$ onto the glassy carbon (4-mm diameter) of the ring disk electrode and then drying at room temperature. Loading amount of the catalysts was $50 \mu \mathrm{g} \mathrm{cm}^{-2}$ $\left(2.5 \mu \mathrm{g}_{\mathrm{Pt}} \mathrm{cm}^{-2}\right)$. The ORR responses were recorded with a $10 \mathrm{mV} \mathrm{s}^{-1}$ scan rate in an $\mathrm{O}_{2}$-saturated electrolyte (rotating speed: 900 r.p.m., scan range: 0-1.1 $V_{\mathrm{RHE}}$ ). ORR results were presented after subtraction of the currents measured in an $\mathrm{N}_{2}$-saturated $0.1 \mathrm{M} \mathrm{HClO}_{4}$ electrolyte to remove capacitances. $\mathrm{H}_{2} \mathrm{O}_{2}$ selectivity and number of electrons transferred $(n)$ were calculated from RRDE tests (equations 2 and 3), which were carried out by applying $1.2 V_{\mathrm{RHE}}$ on the ring disk of the working electrode at a 900 r.p.m. speed.

$$
\begin{gathered}
\mathrm{H}_{2} \mathrm{O}_{2} \text { yield : } \mathrm{H}_{2} \mathrm{O}_{2}(\%)=200 \times \frac{I_{\mathrm{R}} / N}{I_{\mathrm{D}}+I_{\mathrm{R}} / \mathrm{N}} \\
\text { Number of electrons transferred }: n=4 \times \frac{I_{\mathrm{D}}}{I_{\mathrm{D}}+I_{\mathrm{R}} / \mathrm{N}}
\end{gathered}
$$

where $I_{\mathrm{R}}$ is the ring current, $I_{\mathrm{D}}$ is the disk current and $N$ is the collection efficiency ( 0.2 of $\mathrm{N}$ was used after calibration). CO-stripping voltammetry was obtained from two cycles of cyclic voltammetry with a $50 \mathrm{mV} \mathrm{s}^{-1}$ scan rate (scan range: $0-1.2$ $\left.V_{\mathrm{RHE}}\right)$. Before the CO-stripping analysis, $\mathrm{CO}$ molecules were adsorbed on $\mathrm{Pt}$ surface at $0.1 V_{\mathrm{RHE}}$ for $30 \mathrm{~min}$, and then $\mathrm{N}_{2}$ was purged into the electrolyte to remove dissolved $\mathrm{CO}$ gas.

The PDR was carried out by dispersing $10 \mathrm{mg}$ catalysts in $10 \mathrm{mM} \mathrm{H}_{2} \mathrm{O}_{2}$ solution $(50 \mathrm{ml})$. After specified time intervals, $5 \mathrm{ml}$ solution was collected and then $\mathrm{H}_{2} \mathrm{O}_{2}$ concentration was determined by iodometry. The PRR was carried out following the same method for ORR except for the use of an $\mathrm{N}_{2}$-saturated $0.1 \mathrm{M} \mathrm{HClO}_{4}$ electrolyte containing $10 \mathrm{mM} \mathrm{H}_{2} \mathrm{O}_{2}$. $\mathrm{CN}^{-}$-poisoning test was also carried out following the same method for ORR but using an $\mathrm{O}_{2}$-saturated $0.1 \mathrm{M} \mathrm{HClO}_{4}$ electrolyte containing $10 \mathrm{mM} \mathrm{KCN}$ (precautions for safe handling of $\mathrm{KCN}$ in acid solution were considered).

$\mathrm{H}$-cell was operated using $1 \mathrm{M} \mathrm{HClO}_{4}$ as both an anolyte and a catholyte $(5 \mathrm{ml}$ each), and the electrolytes were separated by a Nafion 115 membrane $\left(3 \times 5 \mathrm{~cm}^{2}\right.$, DuPont). The working electrode (cathode) was prepared by spraying of the catalyst inks ( $50 \mathrm{mg}$ catalysts $+250 \mathrm{mg}$ Nafion solution $(5 \mathrm{wt} \%)+5 \mathrm{ml}$ isopropyl alcohol) onto a carbon paper (W1S1005, CeTech). The catalyst loading was $2 \mathrm{mg} \mathrm{cm}^{-2}$ and the geometric active surface area of the electrode was $2 \times 2 \mathrm{~cm}^{2}$. The commercially obtained Pt gas diffusion electrode $\left(1 \mathrm{mg}_{\mathrm{Pt}} \mathrm{cm}^{-2}\right.$, Fuel Cell Earth) was used as an anode. The $\mathrm{H}$-cell was operated at $278 \mathrm{~K}$ under short-circuit condition $(V=0) . \mathrm{H}_{2}$ $\left(100 \mathrm{ml} \mathrm{min}^{-1}\right)$ and $\mathrm{O}_{2}\left(300 \mathrm{ml} \mathrm{min}^{-1}\right)$ gases flowed at an ambient pressure to the anode and cathode channels, respectively. After reaction for specified time intervals, part of the catholyte was collected and then titrated by iodometry to determine $\mathrm{H}_{2} \mathrm{O}_{2}$ concentration.

DFT calculations. Unrestricted DFT calculations were performed using Jaguar 8.2.12 (ref. 62) with the exchange-correlation function of Perdew-Burke-Ernzerhof combined with semiempirical dispersion correction of $u l g$. We used a LACVP $^{* *}$ basis set describing Pt atom with LANL2DZ effective core basis set ${ }^{63}$, while the other atoms with a standard Pople's 6-31G** basis set.

We calculated Gibbs free energy change for each step using Born-Haber thermodynamic cycle scheme (Supplementary Fig. 20). The gas phase Gibbs free energy changes were calculated using 
$\Delta G_{\text {gas }}^{\mathrm{o}}=\Delta E_{\text {el. }}+P \Delta V+\left(\Delta E_{\text {trns. }}+\Delta E_{\text {rot. }}+\Delta E_{\text {vib. }}\right)-T\left(\Delta S_{\text {trns. }}+\Delta S_{\text {rot. }}+\Delta S_{\text {vib. }}\right)$. Here $\Delta E_{\text {el. }}$ is the electronic energy difference computed from DFT self-consistent field energies, $\Delta E_{\text {trns. }}$ and $\Delta S_{\text {trns. }}$ are translational energy and entropy difference, respectively, computed using ideal gas partition function, $\Delta E_{\text {rot. }}$ and $\Delta S_{\text {rot. }}$ are rotational energy and entropy difference, respectively, computed using rigid rotor partition function, and $\Delta E_{\text {vib. }}$ and $\Delta S_{\text {vib. }}$ are vibrational energy and entropy difference, respectively, computed using harmonic oscillator partition function coupled with vibrational frequency calculations (zero-point energy corrections are included). The solvation free energies, $\Delta G^{0}$ sere calculated using PoissonBoltzmann implicit solvation method self-consistently coupled with DFT charge densities ${ }^{64,65}$. Here we set dielectric constant and probe radius to 80.37 and $1.40 \AA$, respectively, to account for the water solvation.

To assess the reaction free energy of redox reactions, the chemical potential of an electron, $\mu\left[\mathrm{e}^{-}\right]$should be defined. To use the internal reference within the DFT calculation framework ${ }^{66,67}$, we calculated the absolute half-cell potential of ferrocene. This leads to $\mu\left[\mathrm{e}^{-}\right]=\left[-4.896-U\right.$ (versus $\left.\left.\mathrm{Fc} / \mathrm{Fc}^{+}\right)\right] \mathrm{eV}$ (ref. 68), which is converted into $\mu\left[\mathrm{e}^{-}\right]=[-4.516-U$ (versus RHE) $] \mathrm{eV}$. The chemical potential of a proton, $\mu\left[\mathrm{H}^{+}\right]$, which is also required to fully assess the reaction free energy of PCET, is set as $-11.152 \mathrm{eV}$ that is comparable with the experimental proton solvation free energy of -10.95 to $-11.92 \mathrm{eV}$ (refs 69,70 ). We note that these values yield $1.148 V_{\mathrm{RHE}}$ for the DFT calculated thermodynamic potential of the four-electron pathway, and $0.700 V_{\mathrm{RHE}}$ for the DFT calculated thermodynamic potential of the two-electron pathway in consistent with the experimental values.

\section{References}

1. Flytzani-Stephanopoulos, M. \& Gates, B. C. Atomically dispersed supported metal catalysts. Annu. Rev. Chem. Biomol. Eng. 3, 545-574 (2012).

2. Flytzani-Stephanopoulos, M. Gold atoms stabilized on various supports catalyze the water-gas shift reaction. Acc. Chem. Res. 47, 783-792 (2014).

3. Yang, X. F. et al. Single-atom catalysts: A new frontier in heterogeneous catalysis. Acc. Chem. Res. 46, 1740-1748 (2013).

4. Lucci, F. R. et al. Selective hydrogenation of 1,3-butadiene on platinum-copper alloys at the single-atom limit. Nat. Commun. 6, 8550 (2015).

5. Kyriakou, G. et al. Isolated metal atom geometries as a strategy for selective heterogeneous hydrogenations. Science 335, 1209-1212 (2012).

6. Pei, G. X. et al. Ag alloyed Pd single-atom catalysts for efficient selective hydrogenation of acetylene to ethylene in excess ethylene. ACS Catal. 5, 3717-3725 (2015).

7. Zhang, S. et al. Catalysis on singly dispersed bimetallic sites. Nat. Commun. 6, 7938 (2015).

8. Fu, Q., Saltsburg, H. \& Flytzani-Stephanopoulos, M. Active nonmetallic Au and $\mathrm{Pt}$ species on ceria-based water-gas shift catalysts. Science 301, 935-938 (2003).

9. Bruix, A. et al. Maximum noble-metal efficiency in catalytic materials: atomically dispersed surface platinum. Angew. Chem. Int. Ed. Engl. 53, 10525-10530 (2014).

10. Wang, Y. G., Mei, D. H., Glezakou, V. A., Li, J. \& Rousseau, R. Dynamic formation of single-atom catalytic active sites on ceria-supported gold nanoparticles. Nat. Commun. 6, 6511 (2015).

11. Fu, Q., Deng, W., Saltsburg, H. \& Flytzani-Stephanopoulos, M. Activity and stability of low-content gold-cerium oxide catalysts for the water-gas shift reaction. Appl. Catal. B 56, 57-68 (2005).

12. Yi, N., Saltsburg, H. \& Flytzani-Stephanopoulos, M. Hydrogen production by dehydrogenation of formic acid on atomically dispersed gold on ceria. ChemSusChem 6, 816-819 (2013).

13. Qiao, B. et al. Highly efficient catalysis of preferential oxidation of $\mathrm{CO}$ in $\mathrm{H}_{2}$ rich stream by gold single-atom catalysts. ACS Catal. 5, 6249-6254 (2015).

14. Qiao, B. et al. Single-atom catalysis of $\mathrm{CO}$ oxidation using $\mathrm{Pt}_{1} / \mathrm{FeO}_{\mathrm{x}}$. Nat. Chem. 3, 634-641 (2011).

15. Lin, J. et al. Remarkable performance of $\mathrm{Ir}_{1} / \mathrm{FeO}_{\mathrm{x}}$ single-atom catalyst in water gas shift reaction. J. Am. Chem. Soc. 135, 15314-15317 (2013).

16. Wei, $\mathrm{H}$. et al. $\mathrm{FeO}_{\mathrm{x}}$-supported platinum single-atom and pseudo-single-atom catalysts for chemoselective hydrogenation of functionalized nitroarenes. Nat. Commun. 5, 5634 (2014).

17. Shi, Y. et al. Single-atom catalysis in mesoporous photovoltaics: the principle of utility maximization. Adv. Mater. 26, 8147-8153 (2014).

18. Lin, J. et al. Little do more: a highly effective $\mathrm{Pt}_{1} / \mathrm{FeO}_{\mathrm{x}}$ single-atom catalyst for the reduction of $\mathrm{NO}$ by $\mathrm{H}_{2}$. Chem. Commun. 51, 7911-7914 (2015).

19. Matsubu, J. C., Yang, V. N. \& Christopher, P. Isolated metal active site concentration and stability control catalytic $\mathrm{CO}_{2}$ reduction selectivity. J. Am. Chem. Soc. 137, 3076-3084 (2015).

20. Yang, M., Allard, L. F. \& Flytzani-Stephanopoulos, M. Atomically dispersed $\mathrm{Au}-(\mathrm{OH})_{\mathrm{x}}$ species bound on titania catalyze the low-temperature water-gas shift reaction. J. Am. Chem. Soc. 135, 3768-3771 (2013).

21. Kwak, J. H. et al. Coordinatively unsaturated $\mathrm{Al}^{3+}$ centers as binding sites for active catalyst phases of platinum on $\gamma-\mathrm{Al}_{2} \mathrm{O}_{3}$. Science 325, 1670-1673 (2009).

22. Moses-DeBusk, M. et al. CO oxidation on supported single Pt atoms: Experimental and $\mathrm{ab}$ initio density functional studies of $\mathrm{CO}$ interaction with $\mathrm{Pt}$ atom on $\theta-\mathrm{Al}_{2} \mathrm{O}_{3}(010)$ surface. J. Am. Chem. Soc. 135, 12634-12645 (2013).
23. Peterson, E. J. et al. Low-temperature carbon monoxide oxidation catalysed by regenerable atomically dispersed palladium on alumina. Nat. Commun. 5, 4885 (2014).

24. Narula, C. K., Allard, L. F., Stocks, G. M. \& Moses-DeBusk, M. Remarkable NO oxidation on single supported platinum atoms. Sci. Rep. 4, 7238 (2014).

25. Li, Z. Y., Yuan, Z., Li, X. N., Zhao, Y. X. \& He, S. G. CO oxidation catalyzed by single gold atoms supported on aluminum oxide clusters. J. Am. Chem. Soc. 136, 14307-14313 (2014)

26. Yang, $\mathrm{M}$. et al. Catalytically active $\mathrm{Au}-\mathrm{O}(\mathrm{OH})_{\mathrm{x}}-$ species stabilized by alkali ions on zeolites and mesoporous oxides. Science 346, 1498-1501 (2014).

27. Guo, X. et al. Direct, nonoxidative conversion of methane to ethylene, aromatics, and hydrogen. Science 344, 616-619 (2014).

28. Bayram, E. et al. Agglomerative sintering of an atomically dispersed $\mathrm{Ir}_{1} /$ zeolite Y catalyst: Compelling evidence against ostwald ripening but for bimolecular and autocatalytic agglomeration catalyst sintering steps. ACS Catal. 5, 3514-3527 (2015).

29. Yang, M. et al. A common single-site $\mathrm{Pt}(\mathrm{II})-\mathrm{O}(\mathrm{OH})_{\mathrm{x}}-$ species stabilized by sodium on "active" and "inert" supports catalyzes the water-gas shift reaction. J. Am. Chem. Soc. 137, 3470-3473 (2015).

30. Ding, K. et al. Identification of active sites in CO oxidation and water-gas shift over supported Pt catalysts. Science 350, 189-192 (2015).

31. Martinez-Macias, C., Serna, P. \& Gates, B. C. Isostructural zeolite-supported rhodium and iridium complexes: Tuning catalytic activity and selectivity by ligand modification. ACS Catal. 5, 5647-5656 (2015).

32. Zhai, Y. P. et al. Alkali-stabilized $\mathrm{Pt}-\mathrm{OH}_{\mathrm{x}}$ species catalyze low-temperature water-gas shift reactions. Science 329, 1633-1636 (2010).

33. Duan, H. et al. Single-site palladium(II) catalyst for oxidative heck reaction catalytic performance and kinetic investigations. ACS Catal. 5, 3752-3759 (2015).

34. Sasaki, K. et al. Alternative electrocatalyst support materials for polymer electrolyte fuel cells. ECS Trans. 33, 473-482 (2010).

35. Park, S.-A., Kim, D.-S., Kim, T.-J. \& Kim, Y.-T. Strong interaction between Pt and thiolated carbon for electrocatalytic durability enhancement. ACS Catal. 3, 3067-3074 (2013).

36. Prado-Burguete, C., Linares-Solano, A., Rodríguez-Reinoso, F. \& de Lecea, C. S.-M. The effect of oxygen surface groups of the support on platinum dispersion in Pt/carbon catalysts. J. Catal. 115, 98-106 (1989).

37. Sun, S. et al. Single-atom catalysis using Pt/graphene achieved through atomic layer deposition. Sci. Rep. 3, 1775 (2013).

38. Yan, H. et al. Single-atom $\mathrm{Pd}_{1} /$ graphene catalyst achieved by atomic layer deposition: remarkable performance in selective hydrogenation of 1,3-butadiene. J. Am. Chem. Soc. 137, 10484-10487 (2015).

39. Proch, S., Wirth, M., White, H. S. \& Anderson, S. L. Strong effects of cluster size and air exposure on oxygen reduction and carbon oxidation electrocatalysis by size-selected $\mathrm{Pt}_{\mathrm{n}}(\mathrm{n}<=11)$ on glassy carbon electrodes. J. Am. Chem. Soc. 135, 3073-3086 (2013).

40. Zhang, X. et al. Catalytically active single-atom niobium in graphitic layers. Nat. Commun. 4, 1924 (2013).

41. Yang, S., Kim, J., Tak, Y. J., Soon, A. \& Lee, H. Single-atom catalyst of platinum supported on titanium nitride for selective electrochemical reactions. Angew. Chem. Int. Ed. Engl. 55, 2058-2062 (2016).

42. Choi, S. et al. Large-scale synthesis of high-quality zeolite-templated carbons without depositing external carbon layers. Chem. Eng. J. 280, 597-605 (2015)

43. Ma, Z., Kyotani, T. \& Tomita, A. Preparation of a high surface area microporous carbon having the structural regularity of $\mathrm{Y}$ zeolite. Chem. Commun. 2000, 2365-2366 (2000)

44. Yang, Z., Xia, Y., Sun, X. \& Mokaya, R. Preparation and hydrogen storage properties of zeolite-templated carbon materials nanocast via chemical vapor deposition: Effect of the zeolite template and nitrogen doping. J. Phys. Chem. B 110, 18424-18431 (2006).

45. Hsi, H.-C., Rood, M. J., Rostam-Abadi, M., Chen, S. \& Chang, R. Effects of sulfur impregnation temperature on the properties and mercury adsorption capacities of activated carbon fibers (ACFs). Environ. Sci. Technol. 35, 2785-2791 (2001).

46. Calkins, W. H. Investigation of organic sulfur-containing structures in coal by flash pyrolysis experiments. Energy Fuels 1, 59-64 (1987)

47. Kicinski, W., Szala, M. \& Bystrzejewski, M. Sulfur-doped porous carbons: synthesis and applications. Carbon 68, 1-32 (2014).

48. Nishihara, H. et al. A possible buckybowl-like structure of zeolite templated carbon. Carbon 47, 1220-1230 (2009).

49. Hall, M. D., Foran, G. J., Zhang, M., Beale, P. J. \& Hambley, T. W. XANES determination of the platinum oxidation state distribution in cancer cells treated with platinum(IV) anticancer agents. J. Am. Chem. Soc. 125, 7524-7525 (2003).

50. Sellmann, D., Häußinger, D. \& Heinemann, F. W. Synthesis, structures, and reactions of sulfur-rich nickel and platinum complexes with $\left[\mathrm{MS}_{3}\right]$ and $\left[\mathrm{MNS}_{2}\right]$ Cores. Eur. J. Inorg. Chem. 1999, 1715-1725 (1999). 
51. Hou, P. X., Orikasa, H., Itoi, H., Nishihara, H. \& Kyotani, T. Densification of ordered microporous carbons and controlling their micropore size by hotpressing. Carbon 45, 2011-2016 (2007).

52. Rabis, A., Rodriguez, P. \& Schmidt, T. J. Electrocatalysis for polymer electrolyte fuel cells: Recent achievements and future challenges. ACS Catal. 2, 864-890 (2012).

53. Choi, C. H. et al. Hydrogen peroxide synthesis via enhanced two-electron oxygen reduction pathway on carbon-coated Pt surface. J. Phys. Chem. C 118, 30063-30070 (2014)

54. von Weber, A., Baxter, E. T., White, H. S. \& Anderson, S. L. Cluster size controls branching between water and hydrogen peroxide production in electrochemical oxygen reduction at $\mathrm{Pt}_{\mathrm{n}} / \mathrm{ITO}$. J. Phys. Chem. C 119, 11160-11170 (2015)

55. Katsounaros, I. et al. Hydrogen peroxide electrochemistry on platinum: towards understanding the oxygen reduction reaction mechanism. Phys. Chem. Chem. Phys. 14, 7384-7391 (2012).

56. Katsounaros, I., Meier, J. C. \& Mayrhofer, K. J. J. The impact of chloride ions and the catalyst loading on the reduction of $\mathrm{H}_{2} \mathrm{O}_{2}$ on high-surface-area platinum catalysts. Electrochim. Acta 110, 790-795 (2013).

57. Perdew, J. P., Burke, K. \& Ernzerhof, M. Generalized gradient approximation made simple. Phys. Rev. Lett. 77, 3865-3868 (1996).

58. Kim, H., Choi, J. M. \& Goddard, W. A. Universal correction of density functional theory to include London dispersion (up to Lr, Element 103). J. Phys. Chem. Lett. 3, 360-363 (2012).

59. Anderson, A. B. \& Albu, T. V. Catalytic effect of platinum on oxygen reduction an ab initio model including electrode potential dependence. J. Electrochem. Soc. 147, 4229-4238 (2000).

60. Koper, M. T. M. Thermodynamic theory of multi-electron transfer reactions: Implications for electrocatalysis. J. Electroanal. Chem. 660, 254-260 (2011).

61. Moulder, J. F., Stickle, W. F., Sobol, P. E. \& Bomben, K. D. Handbook of X-ray Photoelectron Spectroscopy (Pysical Electronics, 1992).

62. Bochevarov, A. D. et al. Jaguar: a high-performance quantum chemistry software program with strengths in life and materials sciences. Int. J. Quantum Chem. 113, 2110-2142 (2013).

63. Hay, P. J. \& Wadt, W. R. Abinitio effective core potentials for molecular calculations - potentials for $\mathrm{K}$ to Au including the outermost core orbitals. J. Chem. Phys. 82, 299-310 (1985).

64. Tannor, D. J. et al. Accurate first principles calculation of molecular charge-distributions and solvation energies from ab-initio quantummechanics and continuum dielectric theory. J. Am. Chem. Soc. 116, 11875-11882 (1994).

65. Marten, B. et al. New model for calculation of solvation free energies: correction of self-consistent reaction field continuum dielectric theory for short-range hydrogen-bonding effects. J. Phys. Chem. C 100, 11775-11788 (1996).

66. Roy, L. E., Jakubikova, E., Guthrie, M. G. \& Batista, E. R. Calculation of oneelectron redox potentials revisited. Is it possible to calculate accurate potentials with density functional methods? J. Phys. Chem. A 113, 6745-6750 (2009).

67. Konezny, S. J. et al. Reduction of systematic uncertainty in DFT redox potentials of transition-metal complexes. J. Phys. Chem. C 116, 6349-6356 (2012).
68. Pavlishchuk, V. V. \& Addison, A. W. Conversion constants for redox potentials measured versus different reference electrodes in acetonitrile solutions at $25^{\circ} \mathrm{C}$. Inorg. Chim. Acta 298, 97-102 (2000).

69. Tawa, G. J., Topol, I. A., Burt, S. K., Caldwell, R. A. \& Rashin, A. A. Calculation of the aqueous solvation free energy of the proton. J. Chem. Phys. 109, 4852-4863 (1998).

70. Tissandier, M. D. et al. The proton's absolute aqueous enthalpy and Gibbs free energy of solvation from cluster-ion solvation data. J. Phys. Chem. A 102, 7787-7794 (1998).

\section{Acknowledgements}

This work was supported by the Basic Science Research Program through the National Research Foundation of Korea (NRF-2011-0011392) and Korea CCS R\&D Center (KCRC) grant (NRF-2014M1A8A1049256). The work was also supported in part by the Advanced Biomass R\&D centre (ABC-2015M3A6A2066121) and Global Frontier R\&D Program (2013M3A6B1078884) on Center for Hybrid Interface Materials (HIM) funded by the Ministry of Science, ICT \& Future Planning. We acknowledge the Pohang Accelerator Laboratory (PAL) for beamline use. EXAFS experiments at PLS were supported by MEST and POSTECH. C.H.C. acknowledges financial support from the Alexander von Humboldt Foundation. We thank J.S. Choi of the KAIST Analysis centre for Research Advancement (KARA) for the HRSTEM imaging and its analysis.

\section{Author contributions}

C.H.C. and M.C. conceived and designed this study. H.C.K and S.Y. prepared the materials. C.H.C. and H.C.K. collected the physical and electrochemical characterizations. C.H.C., K.J.J.M, H.-T.K. and M.C. analysed the experimental results. S.J.C. carried out the XAFS fittings. M.K. and H.K. performed the DFT studies. C.H.C., M.K., K.J.J.M, H.K. and M.C. wrote the paper.

\section{Additional information}

Supplementary Information accompanies this paper at http://www.nature.com/ naturecommunications

Competing financial interests: The authors declare no competing financial interests.

Reprints and permission information is available online at http://npg.nature.com/ reprintsandpermissions/

How to cite this article: Choi, C. H. et al. Tuning selectivity of electrochemical reactions by atomically dispersed platinum catalyst. Nat. Commun. 7:10922 doi: 10.1038/ncomms10922 (2016).

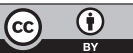

This work is licensed under a Creative Commons Attribution 4.0 International License. The images or other third party material in this article are included in the article's Creative Commons license, unless indicated otherwise in the credit line; if the material is not included under the Creative Commons license, users will need to obtain permission from the license holder to reproduce the material. To view a copy of this license, visit http://creativecommons.org/licenses/by/4.0/ 